\title{
Comensalidade em bares como opção de lazer entre jovens da Zona Norte de Natal/RN
}

\author{
Commensality in drinks bar as option leisure between people young of North Zone \\ Natal/RN
}

\section{Comensalidad en bares como opción de ocio entre jóvenes en la Zona Norte de Natal/RN}

\author{
Keila Regina Santos de Lima ${ }^{1}$ \\ Silvânia Melo da Cunha \\ Sueli Aparecida Moreira ${ }^{3}$
}

\begin{abstract}
Resumo: O convite aos bares como entretenimento e sociabilidade atua como alternativa de lazer, pois expressa diretamente a hospitalidade do lugar visitado. Realizou-se o presente estudo com objetivo de identificar a motivação da frequencia e caracterizar a comensalidade (escolha de companhias para a sociabilidade) nos bares como opção de lazer para jovens da zona norte de Natal/RN. Empregou-se abordagem quali-quantitativa envolvendo 33 indivíduos de ambos os sexos enquanto usufruíam dos serviços dos bares na zona norte de Natal/RN. As categorias analisadas apontam a escolha dos espaços do segmento 'Alimentos \& Bebidas' para a prática do lazer, as motivações para frequência e a experiência da comensalidade no bar. Embora o bar represente uma opção para a prática do lazer para a maioria dos jovens, a falta de opções de lazer restringiu a sociabilidade para a mesa do bar. A comensalidade de jovens nos bares da zona norte reitera a identidade e o pertencimento do jovem comensal no contexto social mais vulnerável da cidade.
\end{abstract}

Palavras-chaves: lazer noturno; lazer cultural; sociabilidade; turismo gastronômico.

Abstract: The invitation to bars for entertainment and sociability acts as an alternative for leisure, as it expresses directly the hospitality of the place visited. In order to identify the motivation behind the frequency and to characterize the commensality (choice of companions for sociability) in the bars as a leisure option for young adults from the north zone of Natal/RN, a quali-quantitative study was conducted involving 33 individuals of both sexes while they enjoyed the services of the bars in the north zone of Natal. The categories analyzed indicate the choice of spaces from the "Food \& Drinks" segment as a leisure practice, the motivations behind the frequency, and the commensality experience in the bar. Although the bar does represent an option of leisure practice for most young people, it is the lack of options that restricts their sociability to the bar table. The commensality of the youth in the north zone bars reiterates the identity and belonging of these young diners in the most vulnerable social context of the city.

Keywords: night leisure; cultural leisure; sociability; gastronomic tourism.

\footnotetext{
${ }_{1}^{1}$ Bacharel em Turismo pela Universidade Federal do Rio Grande do Norte/DETUR/Natal-RN. E-mail: regina.keke@gmail.com Graduanda em Administração pela Universidade Federal do Rio Grande Norte/UFRN-Natal-RN. E-mail: silvaniamelo0508@gmail.com Orcid: https://orcid.org/0000-0002-6160-0355

${ }^{3}$ Professora Adjunta do Departamento de Turismo da Universidade Federal do Rio Grande Norte/UFRN, Natal/RN. E-mail: <suelimoreira@yahoo.com.br> Orcid: https://orcid.org/0000-0002-0558-5808

Pesquisa de Trabalho de Conclusão de Curso em Turismo pela Universidade Federal do Rio Grande do Norte, financiada com recursos próprios dos pesquisadores.
} 
Resumen: La invitación a los bares como entretenimiento y sociabilidad actúa como alternativa para el ocio, ya que expresa directamente la hospitalidad del lugar visitado. Con el fin de identificar la motivación, caracterizar la comensalidad (la elección de los comensales para la sociabilidad) y cómo los bares actúan como una opción de ocio para los jóvenes, se realizó un estudio cuali y cuantitativo en el que participaron 33 personas de ambos sexos, cuando disfrutaban de los servicios de los bares de la zona norte de Natal, Noreste de Brasil. Las categorías analizadas apuntan a la elección de espacios en el segmento 'Food \& Beverage' para la práctica de ocio, las motivaciones de frecuencia y la experiencia de la cena en el bar. Aunque el bar representa una opción para la práctica de ocio para la mayoría de los jóvenes, la falta de opciones de ocio restringió la sociabilidad a la mesa de bar. La conmensalidad de los jóvenes en los bares de la zona norte reitera la identidad y pertenencia de los jóvenes en el contexto social más vulnerable de la ciudad.

Palabras clave: ocio nocturno; ocio cultural; sociabilidad; turismo gastronómico.

\section{INTRODUÇÃO}

A juventude é a fase do desenvolvimento humano em que ocorrem os maiores problemas, desafios e angústias, mas também é a fase onde os indivíduos concentram maior criatividade, energia e potencial para o engajamento político e social. Trata-se de uma fase marcada por processos de desenvolvimento, inserção social e definição de identidades, o que exige experimentação intensa em diversas esferas da vida (FREITAS, 2005, p.31).

A experiência do lazer é de extrema importância para o desenvolvimento psicossocial de jovens. O lazer enquanto cultura - compreendida no seu sentido mais amplo - vivenciada (praticada ou fruída) no tempo disponível" (MARCELINO, 1990). A relação "juventude e diversão" indica que há uma conotação construída historicamente. Estabelecer uma relação entre juventude, lazer e consumo implica considerar elementos socioculturais (BARRAL, 2006) e econômicos que determinam os espaços de lazer que frequentam. As oportunidades para o lazer influenciam as interações dos jovens reiterando suas identidades, moldando aptidões e pertencimento com determinado grupo social.

Embora façam parte do segmento denominado Alimentos \& Bebidas e não sejam classificados diretamente como estabelecimentos de lazer, os bares da Zona Norte de Natal proporcionam a comensalidade como forma de lazer. A concentração dos jovens no próprio bairro decorre do fato de a zona norte localizar-se do outro lado do rio Potengi, demarcando as classes sociais. Quando o lazer envolve o consumo de bebidas alcoólicas agrava-se a dificuldade de transporte, favorecendo a permanência no bairro.

A escolha de companhias para sociabilidade à mesa também pode ser conceituada através da comensalidade, cuja terminologia deriva do latim mensa, que significa conviver à mesa (MOREIRA, 2010). A camaradagem à mesa é uma estratégia de sociabilidade principalmente para jovens. De acordo com Montanari, (2008), a participação à mesa para comer e beber juntos é o primeiro sinal de pertencimento ao grupo.

Sob a perspectiva do turismo, a comensalidade abrange dois dos mais importantes fundamentos da hospitalidade que correspondem ao alimentar e ao entreter (CASTELLI, 2010). Os serviços prestados pelos restaurantes e bares reiteram a importância da gastronomia para o turismo, com a oferta de cardápios regionais e coquetéis, música ao vivo, recursos audiovisuais.

O bar foi escolhido enquanto objeto de estudo por se configurar como um espaço social (BARRAL, 2006), capaz de proporcionar descontração a seus comensais. O bar distingue-se do espaço de casa, da universidade e do trabalho; é o local de vivência da intimidade e da liberdade. As relações de consumo e sociabilidades estabelecidas no bar dão a tônica da vida noturna na Zona Norte de Natal. Então, realizou-se o presente estudo 
com o objetivo de identificar a motivação da frequência e caracterizar a comensalidade nos bares como opção de lazer para jovens da Zona Norte de Natal.

\section{REFERENCIAL TEÓRICO}

\section{JUVENTUDE E DIVERSIDADE}

$\mathrm{Na}$ literatura, os estudos para conceituar ou definir juventude se deparam com certa disparidade e dicotomia. Por um lado é colocada uma faceta da cultura jovem marcada por inúmeros estilos de vida, principalmente quando nos referimos à zona urbana, ressaltando a diferença entre esses diversos grupos de jovens atuantes nesse cenário e a influência que o espaço sociocultural exerce na construção do comportamento e da identidade desses jovens. Por outro lado, parte da literatura apresenta a juventude com aspecto homogêneo, reduzindo-a a uma fase biológica inerente a todo ser humano (FREITAS, 2005).

A mídia, através dos meios de comunicação e de sua influência na formação da opinião pública, também divide a juventude de maneira polar, dual (FRAGA \& JULIANETTI, 2003). Os jovens ora são apresentados em propagandas publicitárias, filmes e novelas como ideal de beleza, saúde e alegria, sempre livres de preocupações e responsabilidades, ditando padrões de vida e consumo, ora a sua imagem é vinculada aos filmes e noticiários, especialmente os sensacionalistas, como a escória da sociedade, envolvidos em problemas com drogas e violência ou comportamentos de risco, e são retratados nessas situações sendo negros e de origem nos setores periféricos e populares da sociedade (FRAGA \& JULIANETTI, 2003).

Tomando por base a bibliografia revisada, faz-se necessário levar em consideração a heterogeneidade de situações e comportamentos da juventude contemporânea. Os jovens são pessoas com potencialidades, necessidades e demandas, mas estão também mais vulneráveis à exclusão se comparados às demais faixas etárias. A juventude é o período de maior desproteção social (PAUGAM, 2003). Portanto, ao se pensar em qualidade de vida faz-se necessário considerar espaços sociais adequados ao desenvolvimento e inclusão social de jovens, favorecendo a construção do projeto de vida e promovendo sua entrada no mundo profissional e social, bem como o uso equilibrado e moderado de aspectos relacionados ao consumo de bebidas alcoólicas.

A juventude brasileira, além da grande diversidade cultural, também tem seu acesso ao lazer e aos espaços de convívios sociais condicionados por fatores socioeconômicos e estigmatizados pela origem e proveniência de moradia.

\section{LAZER E SOCIABILIDADE}

O lazer é um componente específico da vida social, percebido a partir do advento da Revolução Industrial, quando houve uma separação entre os espaços familiares, comunitários e profissionais de maneira que o lazer traz consigo a característica e o aspecto histórico do "não trabalho".

Para Gomes (2014)

[...] reconhecer o lazer unicamente por meio da existência de uma palavra ou de um conceito seria um encaminhamento restrito e insuficiente quando se considera o desafio de problematizá-lo e compreendê-lo de modo situado, isto é, levando em conta algumas das peculiaridades históricas, culturais, sociais, políticas, éticas e estéticas, entre outras, que expressam diversidades e singularidades locais. O reconhecimento dessas particularidades apresenta substanciais desafios para aqueles que buscam problematizar o lazer em diferentes realidades e perspectivas (GOMES, 2014, p. 9). 
O lazer pode ser compreendido enquanto instrumento de desenvolvimento, capaz de contribuir historicamente na formação de jovens, instigando a formulação de valores questionadores da sociedade. Admitir a importância do lazer denota reconhecê-lo como um tempo privilegiado de vivência de valores e de mudança da ordem cultural. Especificamente em relação à juventude:

[...] quando o sujeito se dedica ao trabalho em tempo integral, provavelmente terá ainda menos tempo para o lazer, pois, na maioria das vezes, o trabalho acaba assumindo, precocemente, uma posição de centralidade na vida desses jovens. Além disso, é fundamental destacar que o envolvimento dos jovens com o campo de trabalho se dá principalmente por intermédio de bicos, biscates, freelance ou de outras maneiras ocupacionais caracterizadas pela informalidade (ISAYAMA \& GOMES, 2008, p.163).

A literatura apresenta poucos estudos que tratam do lazer especificamente para a juventude e os que existem, em sua maioria, os jovens são observados como sujeitos de manifestações culturais, analisando o lazer de uma maneira funcionalista, principalmente pela abordagem moralista, onde a escolha do lazer funcionará como ferramenta para afastar o jovem de condições de "má conduta", proporcionando-lhes uma vida mais saudável do ponto de vista da vida em sociedade.

Bourdieu (2008) afirma que a opção de lazer voltada ao consumo de bens culturais mais legítimos depende mais da lógica da oferta do que da lógica da demanda e gostos dos consumidores, pressupondo um trabalho de apropriação e decifração.

Portanto, para realização do presente estudo, optou-se em considerar a frequência aos bares como uma opção de lazer, isentando-nos do papel de julgar os valores morais e atentar para as comensalidades estabelecidas nos bares como oportunidade de lazer e expressões culturais que surgem e são vividas pelos jovens. Simultaneamente, desempenham um ponto de encontro para aliviar as tensões e contradições no cotidiano de periferias urbanas como os da Zona Norte de Natal. De acordo com a citação a seguir é imperativo compreender o que motiva a busca de lazer pelos jovens:

É importante compreender os significados das vivências de lazer dos jovens, tendo em vista identificar se são apenas moda passageira ligada à indústria cultural, ou se constituem novas formas de socialização vivenciadas pela juventude (ISAYAMA \& GOMES, 2008, p.162).

Almeida (2009) descreve que as trajetórias dos jovens refletem o processo de socialização de indivíduos e o gosto de uma geração por meio de movimentos organizados ao longo do tempo. Acabando por partilharem linguagens, valores, símbolos e signos igualmente diferentes.

[...] os processos sociais que afetam os jovens não podem ser compreendidos como exclusivamente resultantes de determinações sociais ou posicionamentos de classe, mas também não seria correto pensar que o principal atributo da juventude seja pertencer a uma determinada "fase de vida" (ALMEIDA, 2009, p. 92).

A juventude é socialmente idealizada como uma fase plena da vida e como um modelo de beleza e saúde, contudo existe uma forte demanda por melhores opções de lazer para além daquelas de domínio cultural e de apelo publicitário e ou que restringem os jovens simplesmente como "nicho de mercado". 


\section{O CONTEXTO DA ZONA NORTE DE NATAL}

A Zona Norte do município de Natal-RN foi a área escolhida para a aplicação das entrevistas com jovens comensais e tem por nome oficial Região Administrativa Norte de Natal. O uso como espaço urbano é considerado novo em relação às demais regiões administrativas da cidade. Sua criação deu-se através de duas políticas de Estado: a construção de conjuntos habitacionais e também do Distrito Industrial de Natal (DIN), na década de 1970. Contudo, o desenvolvimento e a ocupação habitacional desta região administrativa somente tornaram-se possível após a construção da ponte Presidente Costa e Silva, conhecida como "Ponte de Igapó", de acordo com a Semurb (2003):

A Zona Norte de Natal compreende uma área de $57,68 \mathrm{~km}^{2}$, correspondendo a $39,4 \%$ do território municipal, sendo a maior região administrativa da cidade, que é composta por sete bairros: Igapó, Nossa Senhora da Apresentação, Lagoa Azul, Pajuçara, Redinha, Potengi e Salinas. Os limites territoriais dessa região são os seguintes: a Leste, o estuário do Rio Potengi-Jundiaí e com o Oceano Atlântico; a Oeste e ao Sul, limite com São Gonçalo do Amarante e por fim, a Norte com o município de Extremoz (SEMURB, 2003).

O Censo do IBGE de 2010 informa que a população da Zona Norte de Natal é de 303.453 habitantes, compreendendo $37,89 \%$ da população da cidade. A construção da Ponte de Igapó, além de ter atraído investimentos para a região como os já citados: implantação dos conjuntos habitacionais bem como o DNI, possibilitou também que a Zona Norte deixasse de ser demograficamente rural, passando por um processo de urbanização que agrupou a Zona Norte ao cenário urbano de Natal. Com isso, ocorreu uma valorização imobiliária e, a partir da década de 1990, os principais empreendimentos comerciais e de serviços vão se estabelecer nesta região. Contudo, este fato trouxe consequências:

Característica própria do comércio e serviço - localizar-se próximo ao consumidor - teve início a uma "periferização" de suas atividades, nas quais empresas de diversos segmentos começaram a abrir filiais da Zona Norte. Tal fato representa um dos rebatimentos do processo da expansão urbana da cidade (AZEVEDO \& MEDEIROS, 2013, p.44).

Os espaços mais afastados e periféricos da Região Administrativa Norte estão ocupados por loteamentos irregulares, com moradias precárias, que contam com assistência ínfima do Poder Público. Esse descaso provoca uma segregação ainda maior dos jovens provenientes da Zona Norte em relação ao restante da cidade.

Dentre os avanços para a região administrativa Zona Norte foram as construções do Complexo Viário Ulisses de Góis e da Ponte Newton Navarro, popularmente chamada de "Ponte Nova". Essas melhorias na infra-estrutura possibilitaram novas pretensões de mercado para a Zona Norte. No caso da ponte, é interessante observar ainda o aumento do fluxo turístico ao litoral norte (que ultrapassa os limites geográficos da Zona Norte e de Natal). Por último, outro ponto relevante foi a recente construção do aeroporto de São Gonçalo do Amarante, investimento que vem influenciando diretamente a vida dos moradores da Zona Norte, ao tornar-se uma rota de pessoas e mercadorias, atraindo a atenção de empresários (AZEVEDO \& MEDEIROS, 2003).

\section{O BAR COMO ESPAÇO DE CELEBRAÇÃO}

Discutir a respeito de bares envolve abordar diretamente o consumo de bebidas alcoólicas e, sobretudo, convém mencionar a dimensão celebrativa de ocasiões e motivos das comemorações. Portanto, durante a revisão da literatura, a busca bibliográfica concentrou-se em fazer um breve histórico do consumo de bebidas, em especial no Brasil.

Desde tempos remotos a bebida alcoólica é consumida em todo mundo. As razões para tal ato permeiam desde questões médicas ou higiênicas, passando por função afrodisíaca, ou simples e comumente por mero divertimento. Santos (2011) cita o culto 
grego antigo a Dionísio (Baco, para os romanos), considerado o deus do vinho, promotor da civilização e da paz; protetor da agricultura e do teatro. A palavra simpósio é conceituada pelo autor como uma reunião para beber, onde homens debatiam, discutiam, fanfarronavam, conspiravam e celebravam a apresentação de jovens rapazes à sociedade.

No Brasil, a História da Alimentação traz o primeiro relato sobre o uso e a fabricação de bebidas inebriantes através do alemão Hans Staden, por volta de 1954, quando foi prisioneiro de índios brasileiros e lançado em livro três anos depois:

[...] Quando bebem assentam-se ao redor dos potes, alguns sobre achas de lenha e outros no chão. As mulheres dão-lhes a bebida por ordem. Alguns ficam de pé, cantam e dançam ao redor dos potes.

O beber dura a noite inteira; às vezes, também dançam por entre fogueiras e, quando ficam bêbados, gritam, tocam trombetas e fazem um barulho formidável. Raro ficam zangados uns com os outros. São também muito liberais, e o que Ihes sobra em comida repartem com os outros (CASCUDO, 2004, p.770).

As celebrações africanas possuíam ritmo lúdico semelhante às celebrações indígenas brasileiras. Há um registro feito em 1592, na região da África Oriental, pelo jesuíta André Fernandes: "Às vezes, tem festa de beber que dura três, quatro dias sem comer. $\mathrm{O}$ seu vinho é de frutas e de toda a maneira de mantimentos que comem fazem que bebam a que são muito afeiçoados e bebe um deles como três alemães" (CASCUDO, 2004, p.770).

"Do português é que herdamos o hábito do tira-gosto, comumente algo salgado, mas podendo ser também uma fruta (cajá, abacaxi, caju), sempre acompanhando a bebida. Costume antes desconhecido pelos africanos e indígenas" (CASCUDO, 2004, p.770).

No Brasil colonial, a indústria do açúcar teve papel primordial na fabricação do álcool e também na condição de ebriedade do índio e do negro, pois, com tal advento, houve um aumento considerável na quantidade consumida de bebidas fermentadas. Aconteceu, a partir de então, uma prolongação (ainda maior) nos festejos africanos e brasileiros, de dias e noites. "Devia tê-los agradavelmente surpreendido a rapidez com que se embriagavam com a cachaça, aguardente de cana-de-açúcar, destilada nos primeiros alambiques" (CASCUDO, 2004, p.773).

"Desde quando o brasileiro bebe cerveja?". Desde o fim do século XVIII, quando ocorreu uma invasão de cervejas alemãs, holandesas, inglesas e norueguesas nos mercados do Rio de Janeiro, São Paulo, Salvador e Recife. Após 1808, o gosto pela cerveja popularizou-se, anunciando uma cerveja brasileira:

"essa saudável bebida reúne a barateza a um sabor agradável e à propriedade de conservar-se muito tempo, qualidades estas que serão mais apreciadas à medida que o uso da dita cerveja se tornar mais geral", como publicado no Jornal do Comércio do Rio de Janeiro, em 27 de outubro de 1836 conforme registrou Cascudo, (2004, p.783).

O registro da chegada do gelo industrializado no Rio de Janeiro em 1835 permitiu a popularização do uso da bebida nos bares, quase uma década depois:

Bebia-se nos bares e restaurantes a cerveja gelada e raramente 0 vinho que não se resfriava mecanicamente e com o gelo perdia o gosto. A propagação não se seguiu rápida, mas lentamente para outras paragens, enfrentando a desconfiança à frialdade. Quem popularizou a bebida gelada foi a cerveja, vindo o hábito das cidades e espalhando-se devagar pelo interior do país [...] 'Gelar' a bebida é exigência contemporânea. Dizia-se esfriar (CASCUDO, 2008, p.215).

Pela perspectiva hedonista, o princípio básico para a busca do prazer, enquanto virtude ou como bem supremo possui valor fundamental para o bem maior que é o ser humano (RIZZUTTI, 2002, p.2). Nessa direção, o encontro dos jovens nos bares abre 
espaço para manifestações de alegria e humor em contraposição ao tom sério e formal de outros ambientes, produzindo nos comensais um sentimento de certa maneira hedonista. $\mathrm{O}$ ambiente informal do bar propicia uma forma associativa e coletiva de lazer através do encontro com amigos, colegas de universidade ou do trabalho, onde os indivíduos se sentem menos oprimidos pelos códigos e etiquetas sociais e as relações ganham cores, sons e sabores de celebração.

\section{PROCEDIMENTOS METODOLÓGICOS}

Trata-se de estudo de natureza qualitativa e quantitativa, cujos dados foram obtidos por meio de entrevista semiestruturada, contendo roteiro temático para facilitar a abordagem de jovens em bares da Zona Norte de Natal. Os trinta e três participantes da pesquisa tinham entre dezoito e vinte e nove anos e todos residiam, pelo menos, há um ano em bairros da Zona Norte. A coleta de dados foi realizada com a ideia de apreender nos depoimentos deles, atitudes e motivações em relação à convivência estabelecida nos bares e botecos estudados.

$\mathrm{O}$ instrumento de coleta dos dados foi dividido em duas partes, sendo a primeira contendo o perfil sócio demográfico: idade, sexo, endereço, o tempo de permanência com mesmo endereço, escolaridade e o número de pessoas com que se divide o lar. $\mathrm{E}$ a segunda etapa foi constituída de perguntas diretamente relacionadas à motivação da frequência e caracterização da comensalidade do jovem nos bares.

Os bares e botecos onde se coletaram os dados dos jovens comensais foram selecionados a partir da importância sociocultural que possuem para os habitantes da denominada Zona Norte de Natal. No recorte empírico estão contidos os bares mais populares da região com elevada frequência pelo público jovem e que deram as permissões necessárias para aplicação do questionário (preenchido pelos respectivos jovens), sendo eles: Amarelinho Bar, Betto's Bar e O Bar do Pirão.

A coleta de dados ocorreu no período noturno, após às 20:00 horas, nos finais de semana (dias de maior fluxo de clientes) durante o mês de outubro de 2014. Aos jovens foi dado o livre direito de se recusar a participar, cumprindo os aspectos éticos da Resolução 466/2012 do Ministério da Saúde. Por meio do Termo de Consentimento Livre e Esclarecido constava a participação voluntária, confidencial, com preservação do anonimato e sobre a garantia de que os dados seriam utilizados somente para fins acadêmicos. A coleta no interior dos Restaurantes e Bares foi autorizada oficialmente pelos proprietários.

\section{Resultados e discussão}

A amostra de jovens entrevistados foi bastante homogênea em relação à escolaridade. A maioria dos entrevistados estava cursando a Universidade. Alguns tinham a formação de nível superior concluída e apenas um dos jovens entrevistados afirmou ter concluído uma pós-graduação.

Quadro 1. Escolaridade dos entrevistados. $(n=33)$

\begin{tabular}{|c|l|}
\hline $\mathbf{3}$ & Ensino Fundamental Completo \\
\hline $\mathbf{1 2}$ & Ensino Médio Completo \\
\hline $\mathbf{1 3}$ & Ensino Superior Incompleto \\
\hline $\mathbf{4}$ & Ensino Superior Completo \\
\hline $\mathbf{1}$ & Pós Graduação \\
\hline
\end{tabular}

Fonte: Pesquisa DETUR/UFRN, 2014. 
A prática do lazer foi abordada através da questão: "Qual sua forma favorita de praticar o lazer em seu tempo livre?" As respostas obtidas foram categorizadas e as atividades mais frequentes incluíam estar em companhia de pessoas com as quais possuem laços afetivos e a prática de esportes.

O lazer tem importante relação com a construção da identidade do jovem, uma vez que esta é uma fase da vida caracterizada pela "transição", na qual se busca constantemente um "vir a ser" na construção do presente através da superação da infância (ISAYAMA \& GOMES, 2008). Sendo assim, o lazer como dimensão da cultura surge como espaço beneficiado de símbolos, práticas, representações e rituais no qual o jovem busca demarcar sua identidade. É através da música, da dança, da festa e de diversas manifestações culturais que se expressa e se insere no mundo, construindo-o e reconstruindo-o.

O lazer representa a necessidade de fruir, ludicamente, as incontáveis práticas sociais constituídas culturalmente. Essa necessidade concretiza-se na ludicidade e pode ser satisfeita de múltiplas formas, segundo os valores e interesses dos sujeitos, grupos e instituições em cada contexto histórico, social e cultural. (GOMES 2014, p. 12).

Na percepção dos jovens, o simples fato de estar em companhia de pessoas com laços afetivos constitui por si só uma forma de vivência do lazer. A experiência de lazer durante a comensalidade se coaduna com o processo de socialização e individualização notados no estudo de Moreira (2014). A autora identificou um declínio na comensalidade de jovens com amigos e fora de casa em decorrência do processo de individualização durante as refeições.

A socialização é vivenciada quando o jovem assume o seu papel na sociedade, de seus valores e de seus papéis, a partir do seu posicionamento e representação, frente às suas próprias exigências, fazendo a mediação com todas as influências que lhe são disponibilizadas (GIMENES et al., 2004).

Em resposta à pergunta sobre os lugares que os jovens mais gostam de frequentar, organizadas de acordo com os seguimentos de cultura e lazer (Quadro 2 e Quadro 3), observa-se uma baixa frequência de atividades culturais.

Quadro 2. Práticas de lazer favoritas entre jovens de Natal/RN. ( $n=33)$

\begin{tabular}{|c|c|}
\hline $\mathbf{1 9}$ & Práticas Esportivas \\
\hline $\mathbf{7}$ & Desfrutar de laços afetivos \\
\hline $\mathbf{7}$ & Atividades culturais diversas \\
\hline
\end{tabular}

Fonte: Pesquisa DETUR/UFRN, 2014.

Quadro 3. Locais preferidos de jovens para o lazer em Natal/RN. ( $n=33)$

\begin{tabular}{|c|c|}
\hline $\mathbf{2 0}$ & Estabelecimentos de A\&B \\
\hline $\mathbf{1 0}$ & Ambientes Naturais/Esportivos \\
\hline $\mathbf{3}$ & Estabelecimentos Culturais \\
\hline
\end{tabular}

Fonte: Pesquisa DETUR/UFRN, 2014.

Segundo Isayama e Gomes (2008), a valorização da cultura dirigida ao público jovem embora favoreça uma exploração comercial, contribui como estímulo aos movimentos de protesto que estão ligados ao lazer. A centralidade do consumo e da produção cultural em torno do jovem proporciona a visualização de novos espaços, novos tempos e novas formas de produção e formação, tendo os jovens como protagonistas sociais deste processo. Contudo, é importante ressaltar que os jovens sofrem pressões constantes em relação à busca de vida profissional de sucesso, o que acaba por limitar o tempo dedicado ao lazer (ISAYAMA E GOMES, 2008).

A cultura influencia a percepção de mundo que cerca os indivíduos, do tempo e os valores culturais que se constroem, definem e modificam a maneira de utilização do tempo e a 
priorização de atividades que serão realizadas. De acordo com Pierre Bourdieu (2008), as necessidades culturais são produtos da educação, ou seja, a preferência e prática do lazer em matéria de cultura são restritas, com pouca opção de escolha, pois obedecem às determinações do meio social do jovem, no caso.

Comparando a idealização da prática favorita de lazer observa-se no Quadro 2, que a maioria dos jovens entrevistados apreciam as práticas esportivas porém quando interrogados sobre os espaços preferidos que frequentam observa-se que os mesmos optam pelo Estabelecimento de Alimentos e Bebidas/A\&B. A opção por atividades de cunho cultural tem pouco destaque na predileção dos jovens, ficando a interação com parceiros afetivos mais evidentes. No quadro 3, observa-se que os Estabelecimentos Culturais aparecem somente na opinião de 3 jovens. Os estabelecimentos de A\&B, como restaurantes e Bares, suprem de alguma forma essa suposta ficção e condição real de opções de lazer. A frequência aos bares pode configurar-se como uma resposta à baixa oferta de alternativas de lazer na Região estudada. Nesse sentido, Bourdieu (2008) assim expõe:

De fato, por intermédio das condições econômicas e sociais que elas pressupõem, as diferentes maneiras, mais ou menos separadas ou distantes, de entrar em relação com as realidades e as ficções, de acreditar nas ficções ou nas realidades que elas simulam, estão estreitamente associadas às diferentes posições possíveis no espaço social e, por conseguinte, estreitamente inseridas nos sistemas de disposições (habitus) características das diferentes classes e frações de classe (BOURDIEU, 2008 p. 13).

A outra explicação para Estabelecimentos de Alimentos \& Bebidas configurarem-se como os espaços preferidos pode ser devido ao gosto característico da juventude daquela região. Ou então, gostam de praticar esportes, mas encontram interações afetivas nos espaços dos bares. Há um gosto que vai explicar as escolhas sociais desses jovens.

O gosto classifica aquele que procede à classificação: os sujeitos sociais distinguem-se pelas distinções que eles operam entre o belo e o feio. $O$ distinto e o vulgar; por seu intermédio, exprime-se ou traduz-se a posição desses sujeitos nas classificações objetivas (BOURDIEU, 2008, p.13).

Ao analisar a relação lazer/espaço urbano percebemos várias desarmonias que provém do crescimento das cidades, da aceleração e do imediatismo: "[...] pode-se dizer que democratizar o lazer implica democratizar o espaço. E se esse assunto for colocado em termos da vida diária, do cotidiano das pessoas, não há como fugir do fato: o espaço para o lazer é o espaço urbano" (MARCELLINO, 2006, p.25).

Quadro 4. Motivos de jovens para frequentar bares na Zona Norte. Natal/RN, 2014. $(n=33)$

\begin{tabular}{|c|c|}
\hline Motivos & $\mathbf{N}$ \\
\hline 1. Estar na companhia de pessoas com quem se mantém laços afetivos & 13 \\
\hline $\begin{array}{l}\text { “...'Resenha com os parceiros'..." } \\
\text { “...Celebrar o aniversário de um amigo..." } \\
\text { "...Beber com os amigos...” } \\
\text { “...Encontrar amigos...” } \\
\text { “...Conversar com os amigos enquanto tomo uma cerveja gelada...” }\end{array}$ & \\
\hline 2. Válvula de escape do estresse do dia a dia/Descontração & 11 \\
\hline $\begin{array}{l}\text { "...O estresse do dia a dia e também porque gosto de beber nos finais de semana..." } \\
\text { ".... Esesestressar da UFRN" } \\
\text { "...Descontrair, desestressar e sair com amigos..." }\end{array}$ & \\
\hline $\begin{array}{l}\text { 3. A bebida alcoólica em si } \\
\text { "...Porque gosto de beber..." } \\
\text { "...Bebida alcoólica..." }\end{array}$ & 3 \\
\hline 4. O próprio bar em questão & 2 \\
\hline
\end{tabular}




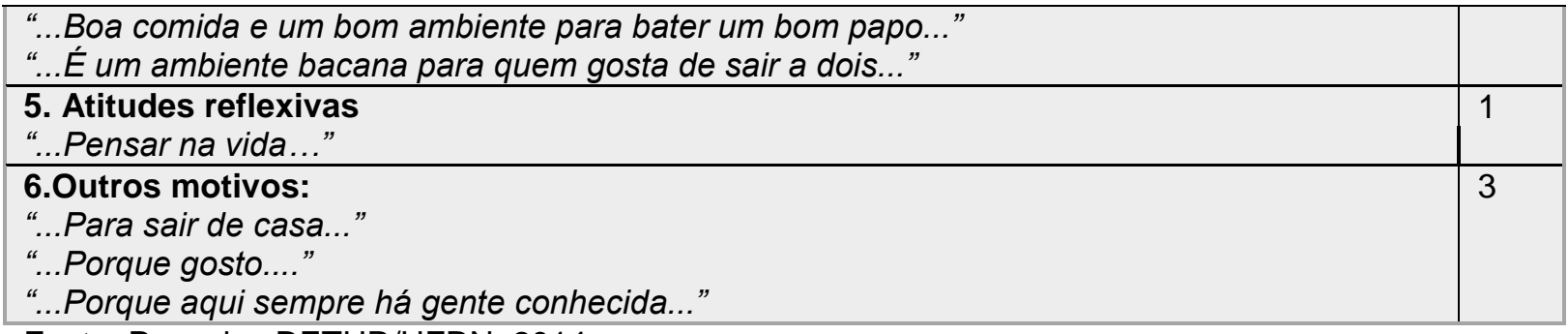

Fonte: Pesquisa DETUR/UFRN, 2014.

Quando se trata de lazer o espaço/lugar vai além do espaço físico, muitas vezes o sujeito se apropria do local na perspectiva de transformá-lo em ponto de encontro consigo mesmo, com o outro e com o mundo, constituindo ativamente a prática do convívio social para o lazer. Embora o bar não seja um espaço específico de lazer, ou seja, "um espaço construído de modo particular para essa função, mas que eventualmente pode cumpri-la" (MARCELLINO, 2006, p.29). Como resultado, a maioria dos jovens entrevistados referiu utilizar o bar como espaço para o lazer; portanto, constitui um ponto de encontro frequente para jovens estudantes.

As motivações relacionadas à frequência dos jovens nos bares (Quadro 4) estiveram relacionadas com a comensalidade ao encontro com parceiros e amigos; aspectos relacionados à descontração; para alívio do estresse e somente alguns deles referiram motivos relacionados diretamente ao bar e ao consumo de bebidas.

Para além do consumo de alimentos e bebidas, o espaço do bar proporciona uma atmosfera que convida ao relaxamento, à diversão e atua como um núcleo no qual são tecidas as relações sociais e, em consequência disso, os encontros se repetirão como forma de gratificar o espaço e reiterar a memória ali desfrutada conjuntamente.

Foi percebida uma característica marcante em todas as respostas obtidas com a pergunta: "Com quem você gosta de vir ao bar?". A grande marca é a convivência com as pessoas com quem já se mantém uma relação de afetividade, seja de amizade, familiar ou até mesmo casual, gerando o esquema de convivência da comensalidade abaixo:

Figura 1. Comensalidades preferidas pelos jovens nos Bares da Zona Norte. Natal, 2014.

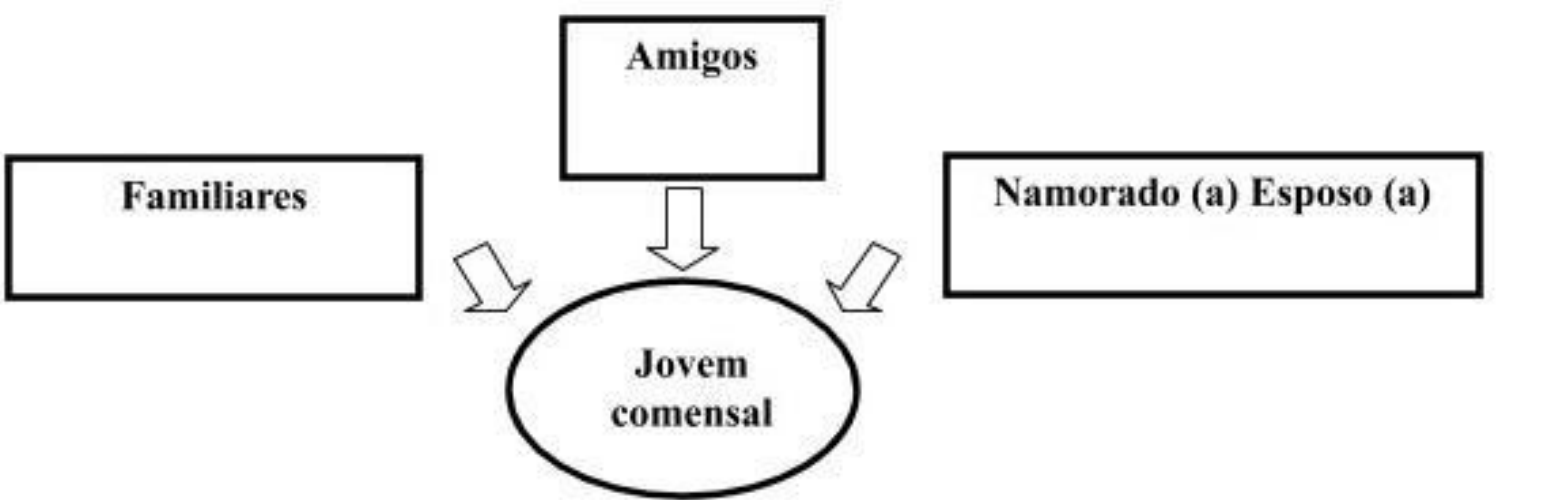

E de suma relevância a observação da escolha da companhia para se estar no bar, vivenciando o lazer, uma vez que ter conhecimento sobre o que se come, quando, como e com quem é ter também conhecimento profundo sobre determinada sociedade. "Comer é a alma de uma cultura" (BOFF, 2006, p.60).

Dentre as motivações citadas percebe-se que a comensalidade é a motivação mais frequente no relato, seguida da busca de companhias específicas pelos jovens que frequentam os bares: 
Comensalidade significa comer e beber junto. $\mathrm{O}$ ato de comer e beber junto foi, e é, momento marcante na vida de todas as comunidades, pois marcam ocasiões em que nutrimos nossos corpos e nossos espíritos, fortificamos nossos relacionamentos, aprofundamos nossas amizades e consolidamos nossas crenças e valores. Assim, a comensalidade, ocasião em que se exerce a hospitalidade, passa a integrar a essência da condição humana (CASTELLI, 2010, p.112).

De maneira que na mesa onde a comensalidade é perpetrada há a aplicação da hospitalidade, que tem por valores de acordo com Castelli (2010), a convivência, a cortesia, a amabilidade e a generosidade. $O$ ato de nutrir-se não é necessariamente apenas uma necessidade fisiológica individual, transcendendo essa necessidade, é o momento de tornarse mais humano, partilhando alimentos e bebidas e celebrando a alegria do encontro e da comunhão.

A comensalidade é considerada o ápice do processo de hospitalidade, através da qual se reconhece a convivência, o respeito e a tolerância, como demonstrado nos dados obtidos nesta pesquisa.

Comensalidade significa comer e beber juntos. Todos se sentam à mesa, como comensais, para comer, beber, comungar e celebrar o estar juntos na mesma Casa Comum, qual grande família humana que se reencontra, todos irmãos e irmãs uns dos outros juntos com os demais seres da criação (BOFF, 2006, p.9).

O bar constitui espaço de convivência, que segundo Castelli (2010, p.158), é uma das dimensões da hospitalidade, uma vez que a vivência está intimamente ligada ao processo de aproximação e conhecimento do outro, que se consolida através "dos atos de trocar, compartilhar, dar, receber e retribuir". Essa vivência fortalece a amizade e o amor, estreitando os laços, sensibilizando o coração e a espiritualidade das pessoas.

A comensalidade favorecida pela bebida tem uma dimensão celebrativa. As celebrações ocorrem desde o período pré-colonial brasileiro, de forma que beber apenas pelo desfastio, divertimento ou desejo pessoal íntimo era um costume que não existia ou quase não existia entre os índios. O índio bêbado isolado é uma herança do contato com o homem branco. "Para os índios, a bebida é sempre função grupal, solenidade com motivação indispensável" (CASCUDO, 2004, p.133).

"Em 1820 Martius não conseguiu promover danças entre coerunas do Amazonas por 'faltarem-lhes', então 'frutos do mato'. Era preciso a colheita de frutos para justificar a reunião, não apenas a base do consumo, mas a intenção simbólica duma festa em louvor da espécie em frutificação, denominando o divertimento. Três dias de dança, canto, fumo e incrível ingestão de bebidas" (CASCUDO, 2004, p.133).

As festas indígenas, apesar de fazerem parte da rotina social da tribo, não faziam parte do cotidiano, do "todo dia", assim como hoje a ida ao bar também não. Nas refeições diárias os índios bebem água pura das fontes e dos rios. "Nenhuma bebida feita acompanhava a comida" (CASCUDO, 2004, p.133).

$\mathrm{Na}$ comensalidade de jovens da Zona Norte, a cerveja era a bebida mais consumida e a apreciação cumpria a dimensão celebrativa. O consumo da cerveja era o ápice do lazer e uma forma de prestigiar o encontro com amigos no espaço do bar.

Do ponto de vista da hospitalidade urbana, a comensalidade é um dos aspectos expressivos da hospitalidade para com outros povos. Cabe recordar que tribos celtas "em tempos antigos, ao se oferecer hospitalidade, oferecia-se comida e bebida aos estrangeiros antes mesmo de se lhes perguntar de onde vinham e porque estavam aí" (BOFF, 2006, p.60).

Nas capitais mais hospitaleiras as mesas se estendem pelas calçadas das ruas convidando turistas para consumo de bebidas e petiscos ou a uma simples pausa para 
descanso. Em Natal, a comensalidade urbana se restringe ao interior dos bares, demandando consumo mínimo para usufruir de mesas com pouca alternativa de lazer ao ar livre, até mesmo à beira mar.

Todos os elementos que precedem o ritual do encontro também são identificados na mesa do bar, de maneira que essa relação acaba por influenciar a construção da identidade dos jovens comensais e, a partir dos diálogos que emergem na atmosfera do bar, surgem questões sociológicas que instigam a reflexão e o posicionamento dos jovens diante da realidade percebida, da cultura e da política.

O lazer no bar como ativismo político desafia o estudo da hospitalidade e turismo, pois abrange:

[..] questões sociológicas como a influência de novas formas de entretenimento no comportamento dos jovens diante da realidade, da cultura, da política. Uma questão que já se coloca, desde os teóricos da indústria cultural e de massa, é a da alienação/passividade dos jovens diante da cultura, da política. O espaço do bar, por exemplo, enquanto prática de lazer pode ser pensado como um espaço de sociabilidade [...], talvez como um espaço outro, de mais liberdade ou regulado por outras normas (BARRAL, 2006, p.5).

Tendo a insensatez justificada pela liberdade da embriaguez, o espaço do bar configura-se como ideal para manifestar posicionamentos, comemorar conquistas, atreverse a um posto de trabalho. Assim como promete a canção de Milton (1981), sob a crença da energia benfazeja da partilha, as expectativas são confiadas à mesa do bar. Afinal, "foi [nos bailes da vida] ou num bar em troca de pão que muita gente boa pôs o pé na profissão".

\section{CONSIDERAÇÕES FINAIS}

A frequência dos jovens do presente estudo nos bares é motivada pela comensalidade em companhia de amigos e de parceiros afetivos. O espaço do bar representa o espaço disponível para lazer para os jovens da Zona Norte. O bar influencia a identidade cultural, a sociabilidade e concentra o convívio dos jovens na região onde residem. A comensalidade do bar atua como forma de lazer, contudo não deveria ser a única opção de lazer disponível para os jovens.

Apesar das restrições legais do consumo de bebidas alcoólicas em relação à idade mínima com proibições legais para condutores, os bares representam uma opção de lazer noturno principalmente para os jovens de residências próximas. Estes ambientes são espaços de sociabilidade influenciados por condições socioeconômicas determinantes para o perfil e a frequência dos jovens comensais.

Sob a perspectiva da hospitalidade e do setor de Alimentos \& Bebidas, os bares são opções de descontração e comensalidade para visitantes e moradores locais. O estudo revela a falta de outras opções de lazer para o público jovem. Contudo, é desejável investimentos em espaços culturais com música e exposição de arte, espaços de incentivo à prática de esportes são opções favoráveis ao desenvolvimento psicossocial do jovem em contexto urbano. A realização de festivais gastronômicos direcionados ao público jovem, contendo competições para elaboração de coquetéis e petiscos poderiam aprimorar a oferta de serviços para o público jovem residente e turista.

A partir da literatura conclui-se que o bar desempenha o papel de espaço disponível para o lazer e como espaço de liberdade que difere da rotina cotidiana. Ainda, a partir da literatura, é possível concluir que o lazer através da comensalidade favorece o respeito a todos os povos e culturas, além de fortalecer a tolerância ativa para se lidar com as diversidades no contexto do Turismo e da Hospitalidade. 


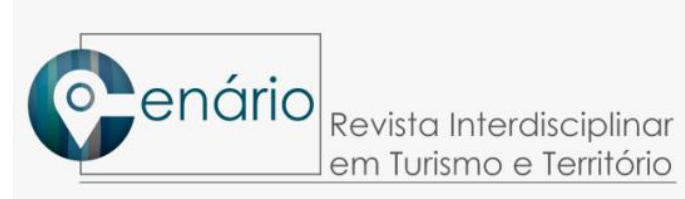

\section{REFERÊNCIAS}

ALMEIDA, M. R. (2009) Cultura como mediação: configurações territoriais e juventude na favela. In: BARROS, J. M. (Org.). As mediações da Cultura: Arte, Processo e Cidadania. Belo Horizonte: Puc Minas, p. 89-109.

AZEVEDO, F.F.; MEDEIROS, T.B. (2013). O uso do território e os circuitos da economia urbana: analisando a Zona Norte de Natal-RN. In: Boletim de Geografia, Maringá, v. 31, n. 2, p. 37-55.

BARRAL, G.L.L. (2006). Espaços de lazer culturas jovens em Brasília: o caso dos bares. (Dissertação). Universidade de Brasília, Brasília.

BOFF, L. (2006). Virtudes para um outro mundo possível. Vol. 3: Comer e beber juntos e viver em paz. Petrópolis/RJ: Vozes.

BOURDIEU, P. (2008). A distinção. Crítica Social do Julgamento. São Paulo: Edusp. 162p.

CASCUDO, L.C. (2004). História da Alimentação no Brasil. 3. ed. São Paulo: Global.

Antologia da Alimentação no Brasil. (2008). 2. ed. São Paulo: Global.

CASTELLII, G. (2010). Hospitalidade: a inovação na gestão das organizações prestadoras de serviços. São Paulo: Saraiva.

FRAGA, P.C.P.; JULIANETTI, J.A.S. (2003). Jovens em tempo real. Rio de Janeiro: DP\&A.

FREITAS, M.V. (2005). Juventude e adolescência no Brasil: referências conceituais. São Paulo: Ação Educativa, p. 31.

GIMENES, M.H.S.G. (2004). Bares e casas noturnas: um estudo exploratório sobre consumo e sociabilidade. In: Turismo em Análise, v. 15, n. 1, 73-88.

GOMES, Christianne Luce. (2014) LAZER: NECESSIDADE HUMANA E DIMENSÃO DA CULTURA. Revista Brasileira de Estudos do Lazer, Belo Horizonte, v. 1, n. 1, p.3-20.

INSTITUTO BRASILEIRO DE GEOGRAFIA E ESTATÍSTICA. IBGE. (2014). Censo Demográfico, 2010. Brasília, IBGE.

ISAYAMA, H.F.; GOMES, C.L. (2008). Lazer, juventude e cultura jovem. In: Lazer e sociedade: múltiplas relações. Campinas/SP: Editora Alínea.

MARCELLINO, N.C. (2006). Estudos do lazer: uma introdução. Campinas/SP: Autores Associados.

MONTANARI, Massimo. (2008). Comida como cultura; tradução de Letícia Martins de Andrade. São Paulo: Editora Senac São Paulo.

MOREIRA, Sueli Aparecida. (2010). Alimentação e comensalidade: aspectos históricos e antropológicos. Cienc. Cult., São Paulo, v. 62, n. 4, p. 23-26.

MOREIRA, Sueli Aparecida. (2014). Ecologia dos convívios comensais de jovens órfãos pela AIDS em São Paulo. Tese de Doutorado - Interunidades em Ecologia Aplicada/USP. 
NASCIMENTO, M.; BRANT, F.(1981). Bailes da vida. Álbum caçador de mim.

PAUGAM, S. (2003). Desqualificação social: Ensaio sobre a nova pobreza. São Paulo: Editora Cortez.

RIZZUTI, E.V. (2002). Hedonismo como conteúdo filosófico do lazer. Santa Cruz do Sul: Funlibre.

SANTOS, S.P. (2011). Comer e beber como Deus manda. São Paulo: Editora Senac/Unesp.

SECRETARIA MUNICIPAL DO MEIO AMBIENTE E URBANISMO - Semurb. (2013). Anuário Natal. Natal: SEMURB.

Recebido em: 05/11/2019 - Aprovado em: 13/12/2019 